\title{
The zinc finger transcription factor PW1/PEG3 restrains murine beta cell cycling
}

\author{
Mozhdeh Sojoodi $^{1} \cdot$ Leslie Stradiot $^{1} \cdot$ Karo Tanaka $^{2} \cdot$ Yves Heremans $^{1}$ • \\ Gunter Leuckx $^{1}$ - Vanessa Besson ${ }^{2}$ - Willem Staels ${ }^{1}$ • Mark Van de Casteele ${ }^{1}$. \\ ${\text { Giovanna } \text { Marazzi }^{2} \cdot \text { David Sassoon }^{2} \cdot \text { Harry Heimberg }}{ }^{2}$ Paola Bonfanti $^{1,3,4}$
}

Received: 26 September 2015 / Accepted: 15 March 2016/Published online: 29 April 2016

(C) The Author(s) 2016. This article is published with open access at Springerlink.com

\begin{abstract}
Aims/hypothesis Pw1 or paternally-expressed gene 3 (Peg3) encodes a zinc finger transcription factor that is widely expressed during mouse embryonic development and later restricted to multiple somatic stem cell lineages in the adult. The aim of the present study was to define $P w 1$ expression in the embryonic and adult pancreas and investigate its role in the beta cell cycle in $P w 1$ wild-type and mutant mice.

Methods We analysed PW1 expression by immunohistochemistry in pancreas of nonpregant and pregnant mice and following injury by partial duct ligation. Its role in the beta cell cycle was studied in vivo using a novel conditional knockout mouse and in vitro by lentivirus-mediated gene knockdown.

Results We showed that PW1 is expressed in early pancreatic progenitors at $\mathrm{E} 9.5$ but becomes progressively restricted to
\end{abstract}

Harry Heimberg and Paola Bonfanti contributed equally to this study

Electronic supplementary material The online version of this article (doi:10.1007/s00125-016-3954-z) contains peer-reviewed but unedited supplementary material, which is available to authorised users.

Harry Heimberg

harry.heimberg@vub.ac.be

$\triangle$ Paola Bonfanti

p.bonfanti@ucl.ac.uk

1 Diabetes Research Center, Vrije Universiteit Brussel, Laarbeeklaan 103, 1090 Brussels, Belgium

2 Stem Cells and Regenerative Medicine Team, Institute of Cardiology and Nutrition, Inserm UMRS-1166, University Pierre and Marie Curie (Paris VI), Paris, France

3 Institute of Child Health, University College London, 30 Guilford Street, WC1N 1EH London, UK

4 Institute of Immunity and Transplantation, University College London, London, UK fully differentiated beta cells as they become established after birth and withdraw from the cell cycle. Notably, PW1 expression declines when beta cells are induced to proliferate and loss of PW1 function activates the beta cell cycle.

Conclusions/interpretation These results indicate that PW1 is a co-regulator of the beta cell cycle and can thus be considered a novel therapeutic target in diabetes.

Keywords Beta cell · Pancreas development $\cdot$ Peg3 · Proliferation $\cdot P w 1$

$\begin{array}{ll}\text { Abbreviations } \\ \text { E } & \text { Embryonic day } \\ \text { P } & \text { Postnatal day } \\ \text { INS } & \text { Insulin } \\ \text { GCG } & \text { Glucagon } \\ \text { PDL } & \text { Partial duct ligation } \\ \text { PDX1 } & \text { Pancreatic and duodenal homeobox 1 } \\ \text { PTF1A } & \text { Pancreas-specific transcription factor 1a } \\ \text { Sh } & \text { Short hairpin }\end{array}$

\section{Introduction}

Under physiological conditions, beta cell division declines continuously after birth in both humans and rodents [1]. In response to increased metabolic demand such as obesity or pregnancy, beta cells can undergo hyperplasia and hypertrophy suggesting that their innate capacity to divide is not lost in the adult [2].

The $P w 1$ (also known as $P e g 3$ ) parentally imprinted gene is unique to placental mammals and encodes a large protein containing a Krüppel-type zinc finger [3, 4]. Chromatin immunoprecipitation sequencing analyses have shown that 
PW1 controls multiple genes that regulate the cell cycle and/or cellular metabolism [5-7]. Furthermore, in vitro studies have shown that PW1 mediates p53-Bax signalling in the p53 growth arrest and cell death pathway activated by DNA damage, possibly by interacting with Siah1 to induce Bax translocation to the mitochondria [8-10]. Consistent with these in vitro studies, loss of $P w 1$ expression correlates with increased cell proliferation and tumour grade in gynaecological and glioma cell lines $[6,7,11]$. Taken together, these studies suggest that PW1 acts as a cell cycle inhibitor and tumour suppressor in multiple cell types. However, $P w 1$ expression, while widespread during early mouse embryonic development [4], is progressively downregulated in most tissues during late embryonic and fetal development. At these stages, high levels of expression are restricted to adult somatic stem cells in several tissues, including skeletal muscle, gut, hair follicles, the central nervous system and bone marrow [12]. The 'pan-stem cell' pattern of $P w 1$ expression in the adult prompted us to examine its expression in the pancreas during embryonic development and adulthood.

\section{Methods}

Mice All animal experiments were approved by our institutional Ethical Committee for Animal Experiments and followed national guidelines and regulations. BALB/c adult and timed pregnant mice were purchased from Janvier Labs (St Berthevin, France). Male C57BL/6 mice of 8 weeks old underwent partial duct ligation (PDL) surgery, as previously described [13]. We generated a new mouse strain with a novel conditional allele, $P w 1^{+/ \text {lox }}$. Male $P w 1^{+/ \text {pat- }}$ mice (F3) were crossed with C57BL/6 female mice (Janvier Lab) to obtain age-matched paternal knockout and wild-type littermates. Four to six mice per cage were maintained under a $12 \mathrm{~h}$ light/dark cycle at $24^{\circ} \mathrm{C}$ and fed a standard diet ad libitum. Pgk ${ }^{\mathrm{Cre}}, \mathrm{Ptfla} \mathrm{Cre}^{\mathrm{Cr}} \mathrm{Ngn} 3^{\mathrm{YFP}}$ and $\mathrm{Ngn} 3^{-/-}$strains were described previously [14-16]. These transgenic mice had mixed genetic backgrounds.

Immunostaining and image analysis Tissue sections and cultured cells were processed for immunostaining as previously described [17]. Sections were incubated overnight at $4^{\circ} \mathrm{C}$ with primary antibodies (electronic supplementary material [ESM] Table 1) diluted in $0.2 \%$ normal donkey serum containing $0.01 \%$ Triton X-100. Cyanine- or DyLight-labelled secondary antibodies were obtained from Jackson ImmunoResearch (Newmarket, UK). The total beta cell volume was analysed as previously described [17-19]. Images were captured with an inverted microscope (Nikon Instruments, Amstelveen, the Netherlands) equipped with a Hamamatsu digital camera c10600 (Olympus, Tokyo, Japan) or with a multiphoton microscope (Zeiss LSM710 NLO with a TiSa laser, NY, USA) and analysed using Smartcapture 3 (version 3.0.8) NIS AR2.30 Imaging Software (Nikon France, Champigny-sur-Marne, France) or Improvision Volocity LE (version 5.0) (PerkinElmer, Waltham, MA, USA) and ImageJ software (https://imagej.nih.gov/ij/) [20].

Lentivirus-mediated gene knockdown A $P w 1$ targeting sequence (5'-GAGTCGCAGTCAATCGATT-3'), loop sequence (5'-TTCAAGAGA-3') and its reverse complement were annealed and cloned into the BglII and HindIII sites of the pSuper.basic vector. Insert-containing clones were selected by PCR and verified by sequencing. Next, an EcoRI-SalI fragment containing the $\mathrm{H} 1$ promoter and the cloned oligo duplex was subcloned into the BamHI-ClaI sites of the pTripGFP vector and co-transfected with the pMD2g and pCMV $\Delta 8.4$ plasmids into 293 T cells, as described previously [21]. Viral vectors were obtained from P. Ravassard (ICM - Institut du Cerveau et de la Moelle épinière, Hôpital Pitié-Salpêtrière, Paris, France) and 293 T cells from ATCC (LGC Standards, Molsheim Cedex, France). Viruses were collected from the culture medium, filtered and concentrated by ultracentrifugation.

RNA analysis Total RNA isolation, amplification and normalisation of data were done as previously described [17]. Primer and probe sequences for quantitative PCR are presented in ESM Table 2.

Statistical analysis Data are expressed as the means \pm SEM of at least three independent experiments and analysed by unpaired two-tailed Student's $t$ test or two-way and one-way ANOVA followed by Tukey's honest significant difference post hoc testing. A $p$ value of $<0.05$ was considered statistically significant. Sample sizes are shown in the figure legends.

\section{Results}

PW1 expression in the pancreas of embryonic and adult mice During the primary transition phase of the developing mouse pancreas (embryonic day [E]9.5-E11.5), PW1 is detected in the nuclei of pancreatic and duodenal homeobox 1 (PDX1) $^{+}$progenitor cells (Fig. 1a). Glucagon-expressing $\left(\mathrm{GCG}^{+}\right)$cells are generated during this period and most contain high levels of PW1 throughout gestation (Fig. 1a, b). In contrast, the number of insulin-expressing $\left(\mathrm{INS}^{+}\right)$cells that express PW1 progressively increases during embryonic development (Fig. 1c). During the secondary transition phase (E13.5-E15.5), the number of $\mathrm{PW} 1^{+} \mathrm{PDX}^{+}$ cells decreases and most PW1 is found in cells lining and near to the exocrine ducts at sites where endocrine progenitor cells become specified (ESM Fig. 1a-c). In addition, in pancreases of Ngn3 knockout mice that lack endocrine cells [14], $\mathrm{PW}^{+}$cells were present in both mutant and wild-type 

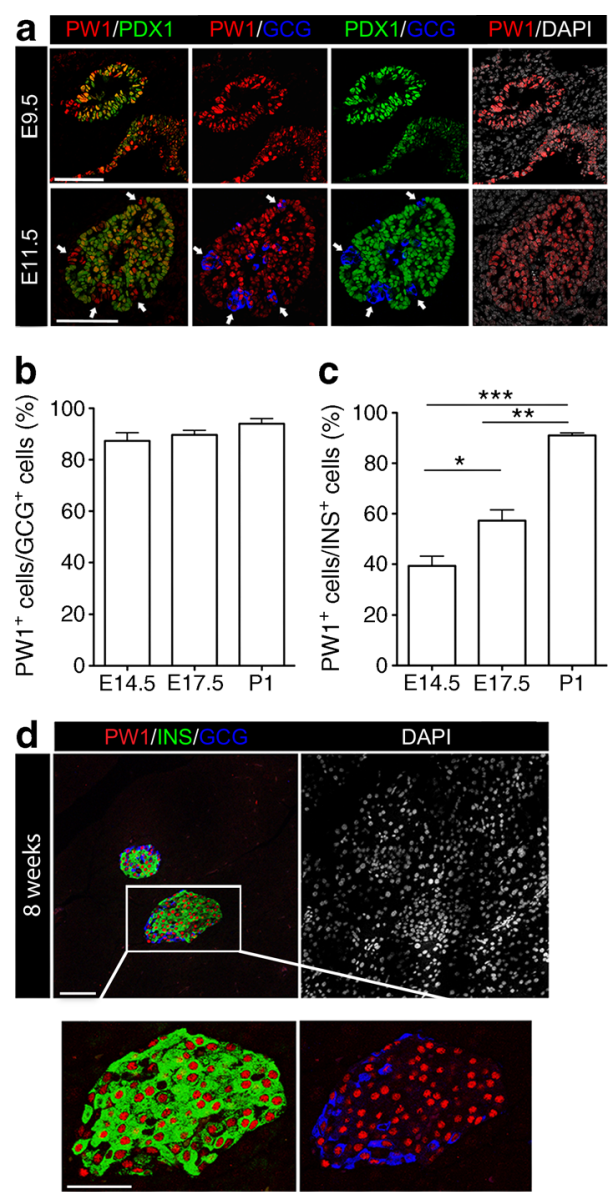

Fig. 1 Biphasic expression pattern of PW1 during pancreatic development. (a) Expression of PW1 (red), PDX1 (green) and GCG (blue) in the pancreases of E9.5 and E11.5 mice. White arrows indicate $\mathrm{GCG}^{+} \mathrm{PW}^{+}$ cells. Scale bars $100 \mu \mathrm{m}$. $(\mathbf{b}, \mathbf{c})$ Relative amounts of $\mathrm{GCG}^{+}$and $\mathrm{INS}^{+}$cells that express PW1 at E14.5, E17.5 and P1 ( $n=3$, mean $\pm \mathrm{SEM},{ }^{*} p<0.05$, $* * p<0.01, * * * p<0.001$; one-way ANOVA). (d) Expression of PW1 (red) in the adult pancreas (INS, green; GCG, blue). Scale bars $50 \mu \mathrm{m}$

littermates at an early stage of pancreatic development (E11.5-E14.5) but absent after endocrine specification (at E17 and later) in Ngn3 knockout mice (ESM Fig. 1d). In the adult pancreas (at 8 weeks old), PW1 was abundant in most beta cells (only $4.64 \pm 0.35 \%$ of INS $^{+}$cells were $\mathrm{PW}^{-}{ }^{-}$) and alpha cells (Fig. 1d) but also in somatostatin ${ }^{+}$delta cells and pancreatic polypeptide ${ }^{+}$cells (data not shown). We conclude that PW1 is expressed in all pancreatic progenitors before endocrine specification and primarily in the endocrine cells after specification.

PW1 restrains the beta cell cycle As PW1 is involved in growth arrest in several cell types, we investigated its presence in cycling beta cells. In the pancreases of embryonic mice at E14.5 and E17.5, as well as in newborn mice, most actively cycling beta cells do not express PW1 (Fig. 2a). In 8-week-old mice, $0.79 \pm 0.17 \%$ of all $\mathrm{INS}^{+}$cells were $\mathrm{Ki}^{+} 7^{+}$; of these, 59 $\pm 8 \%$ were $\mathrm{PW}^{-}$. The number of $\mathrm{PW}^{+}$beta cells in the pancreases of 8 -week-old mice is $4 \%$ higher than in postnatal day 1 (P1) and 14\% higher than in P5. In adult mice, beta cell proliferation can be activated by pregnancy [2] or in response to injury by PDL [22]. The abundance of Pw1 mRNA was decreased in islets from mice at gestation day 15 compared with islets of non-pregnant mice, and also in islets from the ligated part of the pancreas tail after PDL vs after sham treatment (data not shown). Thus, under both conditions, PW1 levels inversely correlated with the beta cell proliferation index (Fig. 2b, c).

To determine whether PW1 plays an active role in controlling the beta cell cycle, we investigated loss of $P w 1$ function in mice derived from a cross between $P g k^{\mathrm{Cre}}$ mice and a novel conditional $P w 1$ allele that we generated, $P w 1^{+/ \text {lox }}$. Offspring from these crosses were bred onto a C57BL/6 background for at least seven generations and the $\mathrm{Cre}$ allele was then eliminated to generate a constitutive PW1-null mutant mouse in which part of $P w 1$ exon 8 and the entire coding domain of exon 9 were deleted. These $P w 1$-null mutant mice, hereafter called $P w I^{+/ \text {pat- }}$, are viable but show a $20 \%$ postnatal growth reduction [23]. The pancreases of 8-week-old $P w 1^{+/ \text {pat }^{-}}$mice lacked PW1 (ESM Fig. 2a) but showed no evidence of gross anatomical abnormalities, exhibited normal cellular architecture in both endocrine and exocrine compartments, and had normal expression patterns of endocrine (PDX1, INS and GCG) and exocrine (amylase and CK19) cell markers (ESM Fig. 2b). However, we noted that the percentage of $\mathrm{Ki} 67^{+}$beta cells was significantly increased in Pw1-null mutant mice compared with their wild-type littermates (Fig. 2d). Remarkably, we did not detect a difference in the levels of DNA damage marker $\gamma-\mathrm{H} 2 \mathrm{aX}$ foci between the two groups (Fig. 2e), suggesting that the higher number of cycling beta cells is not a consequence of increased beta cell death. On the other hand, the total beta cell volume was not increased in pancreas of $P w 1^{+/ p^{-}{ }^{-}}$mice, suggesting that the cell cycle is activated but not completed in beta cells of $P w 1$-null mutant mice.

Beta cell specificity of this phenomenon was examined in $P w I^{+/ l o x}$ mice crossed with Ptfl $1 a^{\mathrm{Cre}}$ mice, which express Cre recombinase under the control of the pancreas transcription factor 1a gene (Ptfla) promoter and hereafter are called Ptfla ${ }^{\mathrm{Cre}} P w 1^{+/ \text {pat- }}$ mice. Notably, the Ptfla promoter is activated in most, but not all, of the early pancreas progenitor $\left(\mathrm{PDX1}^{+}\right)$cells at E9.5 (ESM Fig. 2c, upper panels), and is essential for pancreas specification and function in both mice and humans [15]. Recombination efficiency in the adult beta cells of Ptfla ${ }^{\mathrm{Cre}} P w I^{+/ \text {pat- }}$ mice was $71 \pm 14 \%(n=3)$. PW1 was expressed in $\mathrm{PDX}^{+}$cells and thus also in PTF1A ${ }^{+}$cells from wild-type mice (ESM Fig. 2c, lower panels). The pancreases of Ptfla ${ }^{\mathrm{Cre}} P w 1^{+/ \text {pat- }^{-}}$mice developed normally and showed normal architecture and cell composition (data not shown). However, there was a twofold increase in 
a

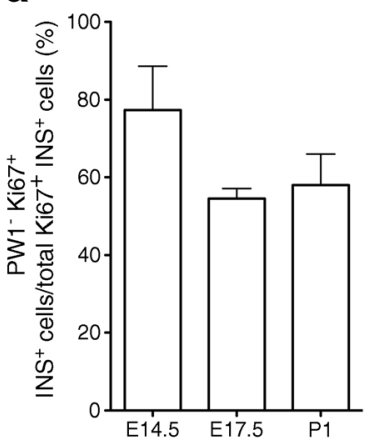

b

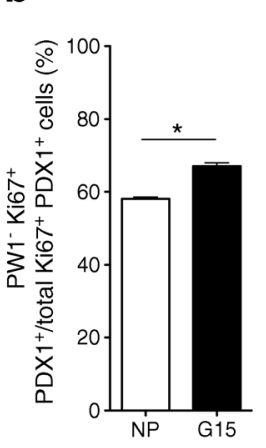

C

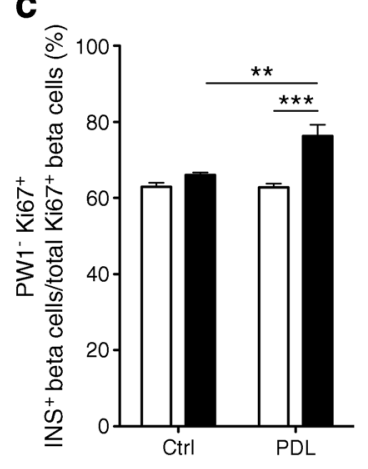

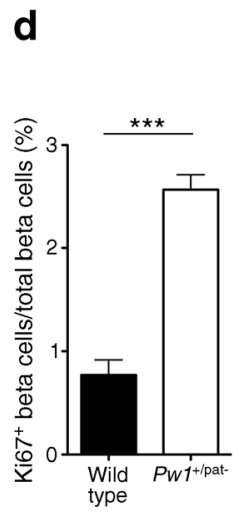

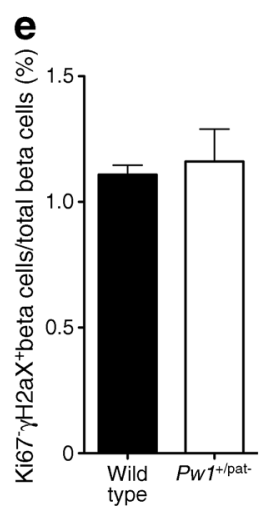

f

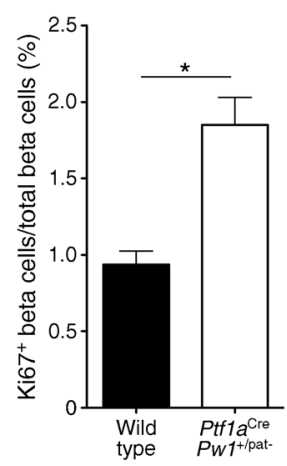

g h
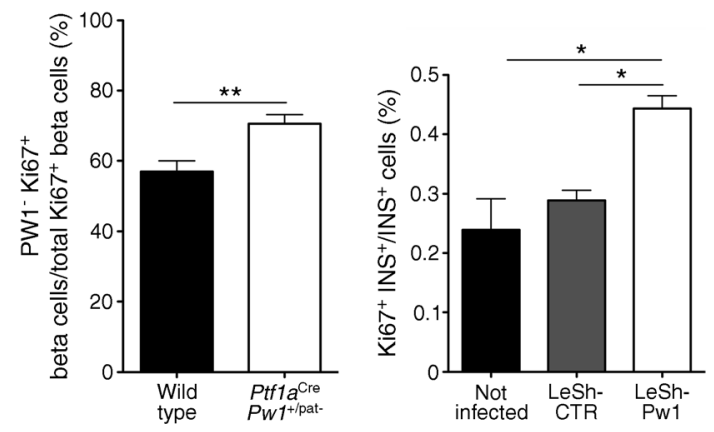

Fig. 2 PW1 expression inversely correlates with beta cell cycling. (a) Percentage of cycling $\left(\mathrm{Ki}_{67}{ }^{+}\right) \mathrm{PW}^{-} \mathrm{INS}^{+}$cells out of the total number of cycling PDX1 ${ }^{+}$cells at E14.5, E17.5 and P1. (b) Percentage of cycling $\mathrm{PW}^{-} \mathrm{PDX1}^{+}$cells at gestational day 15 (G15) out of the total number of cycling $\mathrm{PDX} 1^{+}$cells compared with non-pregnant $(\mathrm{NP})$ mice $(n=3$, mean \pm SEM, ${ }^{*} p<0.05$; Student's $t$ test). (c) Percentage of cycling PW $1^{-} \mathrm{INS}^{+}$ beta cells out of the total number of cycling beta cells in controls (Ctrl) or the ligated (tail, white bars) and unligated (head, black bars) parts of PDL pancreases $(n=3$, mean $\pm \mathrm{SEM}, * * p<0.01, * * * p<0.001$; one-way ANOVA). (d) Percentage of cycling beta cells out of the total number of beta cells in $P w 1^{+ \text {pat- }}$ mice $\left(n=3\right.$, mean \pm SEM, ${ }^{* * *} p<0.001$;

the number of $\mathrm{Ki}_{6} 7^{+} \mathrm{PDX}^{+}{ }^{+}$or $\mathrm{INS}^{+}$cells in the pancreases of 8-week-old Ptfla ${ }^{\mathrm{Cre}} P w I^{+/ \text {pat }^{-}}$mice compared with their wild-type littermates (Fig. 2f). Further, the fraction of Ki67 ${ }^{+}$ beta cells that did not express PW1 was significantly increased (Fig. 2g), demonstrating that actively cycling beta cells are mostly negative for PW1. As Ptfla is not expressed in all pancreatic progenitor cells [15], $P w 1$ was not deleted from the entire progenitor population, and consequently the entire beta cell population, leading to underestimation of the effect of PW1 on beta cell cycling.

To confirm a direct role for PW1 in beta cell cycling, its expression was downregulated by transduction of beta cells with recombinant lentiviruses expressing either a short hairpin (sh)RNA that specifically targets mouse $P w 1$ (LeShPw1) or a control sequence (LeShCTR), together with green fluorescent protein. Infection efficiency at a multiplicity of infection of 100 was at least $65 \%$, and the level of PW1 protein was efficiently reduced in LeShPw1- compared with LeShCTRtransduced cells (ESM Fig. 2d). After 7 days in culture, the
Student's $t$ test). (e) Percentage of $\gamma-\mathrm{H} 2 \mathrm{aX}^{+}$cells out of the total number of beta cells in wild-type and $P w I^{+/ \text {pat }^{-}}$mice. (f) Percentage of cycling beta cells out of the total number of beta cells in wild-type and Ptfla ${ }^{\mathrm{Cre}} P w 1^{+/ \text {pat- }}$ mice $\left(n=3\right.$, mean \pm SEM, ${ }^{*} p<0.05$; Student's $t$ test $)$. (g) Percentage of cycling $\mathrm{PW}^{-}$beta cells out of the total number of cycling beta cells in wild-type and $P t f l a^{\mathrm{Cre}} P w I^{+/ \text {pat- }}$ mice $(n=3$, mean \pm SEM, ${ }^{* *} p<0.01$; Student's $t$ test). (h) Percentage of cycling INS $^{+}$cells out of the total number of INS $^{+}$cells in islet cells either uninfected or transduced with LeShCTR or LeShPw1 $\left(n=3\right.$, mean $\pm \mathrm{SEM},{ }^{*} p<0.05$; one-way ANOVA)

number of $\mathrm{Ki}^{+} 7^{+}$LeShPw1-transduced beta cells had increased 1.5-fold compared with $\mathrm{Ki}_{6} 7^{+}$LeShCTRtransduced beta cells (Fig. 2h). Taken together, our data demonstrate that downregulation of PW1 triggers cell cycle initiation in beta cells.

\section{Discussion}

The present study reports the expression pattern of PW1 in the developing, postnatal and adult pancreas both under healthy conditions and after injury. Our analyses revealed that PW1 co-localises with PDX1 in E9.5 pancreatic buds. At later stages, the expression of PW1 became progressively restricted to pro-endocrine cells, and ultimately to the islets of Langerhans after birth. PDX1, a homeodomain transcription factor necessary for normal development of the pancreas [24], is transiently downregulated during pancreatic lineage specification, and the same spatiotemporal expression pattern is 
seen for PW1. Following endocrine cell specification, PW1 levels increased but only in differentiated endocrine cells. This biphasic pattern of expression is also observed for other key pancreatic transcription factors, including PDX1 [25]. Previous studies have shown that PW1 is found in a wide array of bona fide adult somatic stem/progenitor cells, including those of bone marrow, skin, bone and muscle [12]. Ongoing studies in other tissues show that when PW1 function is lost, the progenitors continue to expand rapidly but fail to self-renew, ultimately resulting in a net loss of progenitor cells and a failure to maintain regenerative capacity. Therefore, the expression of PW1 in beta cells is unusual because these cells are fully differentiated and are consequently not considered to represent a stem cell compartment [26]. Nevertheless, since PDX1 is not only necessary for pancreas specification but also essential for adult beta cells [27] and since PW1 controls the cycling of other cell types [10, 28], we investigated whether PW1 affects beta cell cycling in the embryonic and postnatal pancreas. During pancreatic development, a gradual increase of the number of $\mathrm{PW}^{+} \mathrm{INS}^{+}$cells coincides with a decrease in the beta cell proliferation rate. The number of actively cycling beta cells is decreased in adult compared with neonatal mice, which contain fewer $\mathrm{PW} 1^{+}$ cells. Previous reports revealed that PW1 acts as a p53 mediator through direct interaction with the Siah1 protein to control the cell death pathway and regulate cell cycle arrest via interaction with TNF receptor-associated factor 2 (TRAF2) and Bcl2-associated X (BAX) [10]. Although beta cells respond to stress, we found that the major role of PW1 is to restrain the endocrine cell cycle, a finding that has not previously been reported for primary adult differentiated cells. In addition, conditions that stimulate beta cell proliferation such as pregnancy and pancreatic injury correlated with a decrease in PW1 expression, further supporting a role for PW1 as a negative regulator of the beta cell cycle. Consistent with this proposed role, we observed that loss of PW1 function in mutant mice resulted in significant activation of the beta cell cycle postnatally compared with their wild-type littermates. However, increased beta cell cycling did not result in an increased total beta cell volume, suggesting that PW1 might prime beta cells for proliferation by allowing G1 phase entry, while additional constraints control the continuation and completion of the cell cycle, thus preventing an increase in cell number. Moreover, a shRNA-mediated decrease in PW1 expression in isolated islet cells led to an increased number of actively cycling beta cells. These observations are consistent with the reported function of PW1 in mesoangioblast and glioma cell proliferation and the presence of a specific recognition sequence for PW1 within the cyclin E promoter $[6,28]$.

Taken together, these findings show that PW1 controls initiation of the beta cell cycle both in vivo and in vitro under different physiological and experimental conditions. Future studies to investigate the role of PW1 as a negative regulator of the beta cell cycle may reveal it to be a novel therapeutic target for increasing the number of endogenous beta cells.

Acknowledgements We thank A. Demarré, V. Laurysens, J. De Jonge, E. Quartier and G. Stangé (Diabetes Research Center, Vrije Universiteit Brussel) for their technical assistance.

Funding statement This work was supported by a European Molecular Biology Organization long-term fellowship (no. ALTF 826-2010), a European Foundation for the Study of Diabetes/JDRF Young Investigator Award, a University College London Excellence Fellowship, and grants from the European Research Council (no. ERCStg-2014-639429) and the Rosetrees Trust (no. M362) to PB; and grants from the Vrije Universiteit Brussel Research Council, Stichting Diabetes Onderzoek Nederland, the Fund for Scientific Research Flanders and the Interuniversity Attraction Pole networks to HH. DS, GM and KT were supported by the European Community Seventh Framework Programme project ENDOSTEM (Activation of vasculature associated stem cells and muscle stem cells for the repair and maintenance of muscle tissue; agreement no. 241440), the ANR 'Laboratoire d'Excellence' REVIVE programme, the Institut de Cardiométabolisme et Nutrition (IHU-ICAN) projects and the Fondation Leducq.

Duality of interest statement The authors declare that there is no duality of interest associated with this manuscript.

Contribution statement MS, DS, HH and PB made substantial contributions to the study conception and design; LS, KT, YH, GL, VB and WS acquired the data; MS, YH, MVdC, GM, DS, HH and PB analysed and interpreted the data; and all authors contributed to drafting or critically revising the article and approved the final version for publication. $\mathrm{HH}$ is the guarantor of this work.

Open Access This article is distributed under the terms of the Creative Commons Attribution 4.0 International License (http://creativecommons.org/ licenses/by/4.0/), which permits unrestricted use, distribution, and reproduction in any medium, provided you give appropriate credit to the original author(s) and the source, provide a link to the Creative Commons license, and indicate if changes were made.

\section{References}

1. Teta M, Long SY, Wartschow LM, Rankin MM, Kushner JA (2005) Very slow turnover of beta-cells in aged adult mice. Diabetes 54:2557-2567

2. Rieck S, Kaestner KH (2010) Expansion of beta-cell mass in response to pregnancy. Trends Endocrinol Metab 21:151-158

3. Kuroiwa Y, Kaneko-Ishino T, Kagitani F et al (1996) Peg3 imprinted gene on proximal chromosome 7 encodes for a zinc finger protein. Nat Genet 12:186-190

4. Relaix F, Weng X, Marazzi G et al (1996) Pw1, a novel zinc finger gene implicated in the myogenic and neuronal lineages. Dev Biol 177:383-396

5. Dowdy SC, Gostout BS, Shridhar V et al (2005) Biallelic methylation and silencing of paternally expressed gene 3 (PEG3) in gynecologic cancer cell lines. Gynecol Oncol 99:126-134

6. Jiang X, Yu Y, Yang HW, Agar NY, Frado L, Johnson MD (2010) The imprinted gene PEG3 inhibits Wnt signaling and regulates glioma growth. J Biol Chem 285:8472-8480 
7. Thiaville MM, Huang JM, Kim H, Ekram MB, Roh TY, Kim J (2013) DNA-binding motif and target genes of the imprinted transcription factor PEG3. Gene 512:314-320

8. Johnson MD, Wu X, Aithmitti N, Morrison RS (2002) Peg3/Pw1 is a mediator between $\mathrm{p} 53$ and Bax in DNA damage-induced neuronal death. J Biol Chem 277:23000-23007

9. Schwarzkopf M, Coletti D, Sassoon D, Marazzi G (2006) Muscle cachexia is regulated by a p53-PW1/Peg3-dependent pathway. Genes Dev 20:3440-3452

10. Relaix F, Wei X, Li W et al (2000) Pw1/Peg3 is a potential cell death mediator and cooperates with Siah1a in p53-mediated apoptosis. Proc Natl Acad Sci U S A 97:2105-2110

11. Maegawa S, Yoshioka H, Itaba N et al (2001) Epigenetic silencing of PEG3 gene expression in human glioma cell lines. Mol Carcinog $31: 1-9$

12. Besson V, Smeriglio P, Wegener A et al (2011) PW1 gene/paternally expressed gene 3 (PW1/Peg3) identifies multiple adult stem and progenitor cell populations. Proc Natl Acad Sci U S A 108:11470-11475

13. De Groef S, Luyckx G, Van Gassen N et al (2015) Surgical injury to the mouse pancreas through ligation of the pancreatic duct as a model for endocrine and exocrine reprogramming and proliferation. J Vis Exp 102:e52765

14. Gradwohl G, Dierich A, LeMeur M, Guillemot F (2000) Neurogenin 3 is required for the development of the four endocrine cell lineages of the pancreas. Proc Natl Acad Sci U S A 97:16071611

15. Kawaguchi Y, Cooper B, Gannon M, Ray M, MacDonald RJ, Wright CV (2002) The role of the transcriptional regulator Ptfla in converting intestinal to pancreatic progenitors. Nat Genet 32: $128-134$

16. Herrera PL (2000) Adult insulin-and glucagon-producing cells differentiate from two independent cell lineages. Development 127: $2317-2322$
17. Xu X, D'Hoker J, Stange G et al (2008) Beta cells can be generated from endogenous progenitors in injured adult mouse pancreas. Cell 132:197-207

18. Bogdani M, Lefebvre V, Buelens N et al (2003) Formation of insulin-positive cells in implants of human pancreatic duct cell preparations from young donors. Diabetologia 46:830-838

19. Van de Casteele M, Leuckx G, Baeyens L et al (2013) Neurogenin $3^{+}$cells contribute to beta cell neogenesis and proliferation in injured adult mouse pancreas. Cell Death Dis 4:e523

20. Abramoff MD, Magalhaes PJ, Ram SJ (2004) Image processing with Image J. Biophoton Int 11:36-42

21. Houbracken I, Baeyens L, Ravassard P, Heimberg H, Bouwens L (2012) Gene delivery to pancreatic exocrine cells in vivo and in vitro. BMC Biotechnol 12:74

22. Van de Casteele M, Leuckx G et al (2014) Partial duct ligation: beta-cell proliferation and beyond. Diabetes 63:2567-2577

23. Denizot A-L, Besson V, Correra RM et al (2016) A novel mutant allele of Pw1/Peg3 does not affect maternal behavior and nursing behavior. PlosGenetics (in press)

24. Jonsson J, Carlsson L, Edlund T, Edlund H (1994) Insulinpromoter-factor 1 is required for pancreas development in mice. Nature 371:606-609

25. Offield MF, Jetton TL, Labosky PA et al (1996) PDX-1 is required for pancreatic outgrowth and differentiation of the rostral duodenum. Development 122:983-995

26. Puri S, Folias AE, Hebrok M (2015) Plasticity and dedifferentiation within the pancreas: development, homeostasis, and disease. Stem Cells 16:18-31

27. Fujimoto K, Polonsky KS (2009) Pdx1 and other factors that regulate pancreatic beta-cell survival. Diabetes Obes Metab 11(Suppl 4):30-37

28. Bonfanti C, Rossi G, Tedesco FS et al (2015) PW1/Peg3 expression regulates key properties that determine mesoangioblast stem cell competence. Nat Commun 6:6364 